Cuadernos de Filología Clásica. Estudios Latinos

ISSN: 1131-9062

http://dx.doi.org/10.5209/CFCL.56192

\title{
Los clásicos grecolatinos de la Biblioteca Universal de Joaquín Pi y Margall (II) ${ }^{1}$
}

\author{
J. David Castro de Castro ${ }^{2}$
}

Recibido: 1 de abril de 2016 / Aceptado: 2 de septiembre de 2016

Resumen. Este trabajo se enmarca en el estudio de la divulgación de los clásicos grecolatinos por medio de traducciones publicadas en colecciones españolas a lo largo de los siglos XIX y XX. Se centra en la Biblioteca Universal de Joaquín Pi y Margall, describiendo las características principales de la colección y las de los volúmenes de autores clásicos en ella publicados. La Biblioteca Universal tiene características peculiares que la convierten en un ejemplo representativo de un tipo determinado de divulgación, la dirigida a un público generalista gracias al mantenimiento de un precio muy económico. Los volúmenes en ella publicados lograron, por ello, una notable difusión, pero no sólo entre el público general, sino también entre los intelectuales de la época. Tras haber presentado en la primera parte del trabajo las características generales de la colección y las traducciones que en ella publicó Ángel Lasso de la Vega, abordamos ahora el resto de traductores y versiones y ofrecemos unas conclusiones sobre la relevancia de esta colección como vehículo de difusión de los clásicos.

Palabras clave: Biblioteca Universal; traducción; divulgación.

\section{[en] Greek and Latin Classics in the Biblioteca Universal collection (II)}

Abstract. This work is part of the study of the dissemination of Greek and Latin classics through translations published in Spanish collections in the nineteenth and twentieth centuries. It focuses on the Biblioteca Universal, a collection created by Joaquín Pi y Margall, and describes the collection's main characteristics and those of the classic authors' volumes contained in that collection. The $B i$ blioteca Universal has peculiar characteristics that make it a representative example of a certain type of dissemination, directed at the general public by maintaining a very affordable price. The volumes published in it therefore achieved a wide circulation, not only among the general public but also among the intellectuals of the time. Having presented in the first part of the paper the general characteristics of the collection and the translations published by Angel Lasso de la Vega, it will be studied now the rest of translators and versions and some conclusions on the relevance of this collection as a vehicle for disseminating the classics will be drawn.

Keywords: Biblioteca Universal; translation; classics dissemination.

Sumario: 1. Introducción. 2. Traductores de la BU. 2.1. Eduardo de Mier. 2.1.1. Introducción. 2.1.2. Eurípides (vol. 55). 2.2. Anónimo (¿Rafael Ginard de la Rosa?). 2.2.1. Introducción. 2.2.2. Demóstenes y Esquines (vol. 74). 2.3. Antonio González Garbín. 2.3.1. Introducción. 2.3.2. Plauto y su teatro (vol. 116). 2.4. Fray Luis. 2.4.1. Horacio por fray Luis (vol. 183). 2.4.2. Virgilio por fray Luis (vol. 5). 3. Conclusiones. 4. Referencias bibliográficas.

1 Este trabajo ha sido realizado en el marco del Proyecto de Investigación FFI2015-65964-P, financiado por el MINECO/FEDER.

$2 \quad$ Universidad Complutense de Madrid (España)

E-mail: dcastro@filol.ucm.es 
Cómo citar: Castro de Castro, D., «Los clásicos grecolatinos de la Biblioteca Universal de Joaquín Pi y Margall (II)», Cuad. Filol. Clásc. Estud. Lat. 37.1 (2017), 137-148.

\section{Introducción}

En la primera parte de nuestro trabajo hemos estudiado las versiones de clásicos grecolatinos que en la Biblioteca Universal publicó Ángel Lasso de la Vega (tragedias de Séneca, epigramas griegos, lírica griega, Sófocles, Juvenal y Terencio). Abordamos ahora las versiones del resto de traductores: Eduardo de Mier, un traductor anónimo de Demóstenes y Esquines, Antonio González Garbín y fray Luis de León. Frente a las versiones de Lasso de la Vega, inéditas, en verso y no irreprochables respecto a su corrección (aunque legibles) nos encontraremos traducciones ya publicadas con anterioridad (salvo la anónima de Demóstenes y Esquines), en prosa (salvo las de fray Luis) y algunas de notable calidad científica (sobre todo la de González Garbín y excluyendo la de los oradores griegos).

\section{Traductores de la BU}

\subsection{Eduardo de Mier}

\subsubsection{Introducción}

Eduardo de Mier y Barbe(r)y (1829-1911), de ideología conservadora, estudió Derecho y ocupó diversos cargos públicos, siendo nombrado Secretario de la Comisión Central de Monumentos. Desarrolló una amplia labor periodística como redactor de varios periódicos: El Parlamento, El León Español, El Reino, El Tiempo, La Tribuna, La España y Diario de Barcelona, aunque colaboró además en otros muchos. Estudioso de la literatura clásica y la española, publicó también novelas bajo seudónimo. Como traductor de obras clásicas se ocupó de Eurípides y Esopo, mientras que entre los autores modernos vertió a Schiller y la Historia de la literatura y del arte dramático en España de F. von Schack.

\subsubsection{Eurípides (vol. 55) ${ }^{3}$}

Como señalan M. González y R. González $(2007,110)^{4}$, se trata, en realidad, de una traducción de la Alcestis (aquí llamada Alcestes), de la Medea y de Las Fenicias y, aunque no se indica en portada (sí en la escueta nota ${ }^{5}$ que precede a la traducción firmada por

3 Eurípides, Tragedias, Madrid, Dirección y administración, 1879. Reimpresiones: Madrid, Hernando, 1898; Madrid, Perlado, Páez y Compañía, 1913; Madrid, Sucesores de Hernando, 1920; Madrid, Librería y Casa Editorial Hernando, 1931.

$4 \quad$ M. González y R. González (2007, 107-111) ofrecen los datos fundamentales sobre esta traducción: su primera publicación, la edición de la $B U$ y la $C I A P$ y la aparición de la traducción completa de Eurípides en la Biblioteca Clásica. También sobre esta traducción R. González-M. González (2010, 192-195).

5 «En las trajedias (sic) que en este tomo de la Biblioteca ofrecemos al público, hemos procurado apartarnos lo menos posible de la magnífica traducción castellana del poeta griego, publicada hace años por el distinguido literato D. Eduardo de Mier. Es lástima que no haya visto la luz pública más que un tomo de la versión de los dramáticos griegos, que se proponía darnos a conocer el Sr. Mier. Aun así y todo, en las obras de Eurípides que 
el Editor), la traducción es la de Eduardo de Mier ${ }^{6}$. Se añade al final una «Ojeada General Histórico-crítica sobre las Tragedias de Eurípides» del mismo autor, que es la introducción a su traducción publicada en 1865. Esta traducción en prosa, aunque no carece de omisiones y errores, está hecha, según M. González y R. González (2007, 110 y 2010, 194), directamente del griego.

Es importante señalar que, si bien se indica que el texto de Las Fenicias es una selección, no siempre se explicitan los cortes, de forma que en p. 154 un largo diálogo (correspondiente a los versos 382-442 de la edición de G. Murray) es cortado sin introducir indicación alguna. No es el único caso (lo mismo sucede en p. 156, por ejemplo). Otras veces, como en las pp. 149 y 159, una doble línea de puntos sugiere el corte.

Una cita de esta traducción aparece en el Manual de literatura nacional y extranjera de Hermenegildo Giner de los Ríos (1889, II 110-111). Se ha planteado la posibilidad de que Galdós utilizase esta traducción para preparar su Alceste, pero parece más bien que usó una traducción francesa ${ }^{7}$. Por otro lado, este volumen estaba en la biblioteca de García Lorca (Carmona 2003, 150) y es probable que hubiera muchos más libros de la $B U$ y que algunos se perdieran (Carmona 2003, 147). También estaba este tomo entre los libros del escritor y académico de la Historia Miguel Mancheño y Olivares (Martínez López 2009, 159).

\subsection{Anónimo (¿Rafael Ginard de la Rosa?)}

\subsubsection{Introducción}

Rafael Ginard de la Rosa nació en Manila en fecha desconocida y murió en 1918. Ejerció como periodista, crítico literario, traductor y escritor (como autor de creación escribió poesía, novela, libretos de zarzuela y ópera, así como memorias). Secretario del político Manuel Ruiz Zorrilla, dirigió el periódico El Porvenir, de breve trayectoria, órgano de la corriente del Partido Democrático Progresista que encabezaba Ruiz Zorrilla (Pérez Roldán 1999, 327). También fue Director de El Progreso y El País.

\subsubsection{Demóstenes y Esquines (vol. 74)}

En este volumen encontramos una traducción del discurso Contra Ctesifonte de Esquines y la oración Sobre la Corona de Demóstenes.

El editor de la Biblioteca Universal, Pi y Margall, quiso incluir en la colección una sección de traducciones de oradores de todas las épocas, como señala en la

tradujo, demostró profundo conocimiento de la lengua griega, y en las eruditas notas con que las ilustró, se ven la inteligencia y el saber de un helenista de primer orden» (pp. 6-7).

6 Apareció como Biblioteca de dramáticos griegos: tomo I, Tragedias de Eurípides publicada por la iniciativa y bajo la protección del Excmo. e Ilmo. Sr. D. José Gutiérrez de la Vega y traducida en prosa castellana por Eduardo de Mier, Madrid: [s.n.], 1865 (Imprenta de M. Tello). Incluía únicamente Hécuba, Hypolito, Las Fenicias, Orestes, Alcestes, Medea, Las Troyanas, Hércules Furioso y Electra. Una traducción completa apareció en la Biblioteca Clásica en tres volúmenes (Madrid, 1909-1910).

7 Gountiñas $(1977,470-471)$ dice: «En la biblioteca de Galdós no hemos encontrado el libro que utilizó para preparar esta pieza».

8 Demóstenes y Esquines, Madrid, Dir. y Adm., 1881. Reimpresiones: Madrid, Hernando y Compañía, 1902; Madrid, Hernando y Compañía, 1912; Madrid, Hernando y Compañía, 1919; Madrid, Librería y Casa Editorial Hernando, 1927. 
introducción del tomo 63 dedicado a las obras de Bossuet. Este es el contexto de las versiones de Esquines y Demóstenes. Así, Ginard se encargó ${ }^{9}$-además de las obras estudiadas de Demóstenes y Esquines- de los volúmenes dedicados a Bossuet (Oraciones fúnebres) y Mirabeau (vols. 53 y 54 respectivamente, publicados ambos en 1879) aportando introducciones ${ }^{10}$. Si bien la traducción del volumen de oradores griegos no es atribuida en ningún momento a Ginard, cabe plantear la posibilidad de que sea suya. La omisión del nombre puede deberse a que el texto se basa en traducciones francesas: para Esquines en la de J.-Fr. Stiévenart (1840), luego reimpresa en varias ocasiones y editoriales (por ejemplo, Stiévenart 1843); para Demóstenes en la de Jager-Chappuyzi.

La traducción va precedida por una introducción que sí firma Ginard, reimpresa en el volumen misceláneo ya citado titulado Hombres y obras (153-164) y en la que se percibe el uso de la introducción de la traducción de Stiévenart (5 y sig.), la que utilizará como guía el traductor de Esquines en este volumen. Ello permite pensar que la traducción pueda muy bien ser también de Ginard.

\begin{tabular}{|c|c|}
\hline STIÉVENART 1843 p. x & GINARD p. 15 \\
\hline $\begin{array}{l}\text { Le fils d'une joueuse de tympanon et d'un } \\
\text { pauvre maître d'école, après avoir été tour } \\
\text { à tour athlète, comédien de village, greffier } \\
\text { d'un magistrat subalterne, se sent tout à } \\
\text { coup entraîné vers l'éloquence, et parvient } \\
\text { à disputer la palme oratoire à Démosthène. } \\
\text { Tel est le phénomène que nous admirons } \\
\text { dans Eschine, Athénien du bourg de Ko- } \\
\text { thoce. Né avec un tempérament robuste, il } \\
\text { était doué d'une très-belle voix. Il avait qua- } \\
\text { rante ans lorsqu'il entra dans la carrière po- } \\
\text { litique; et ce fut avec un tel succès, qu'il se } \\
\text { vit chargé des causes les plus importantes, } \\
\text { et de plusieurs ambassades. L'ardente ri- } \\
\text { valité qui s'établit entre lui et Démosthène } \\
\text { lui fit rechercher la faveur de Philippe, } \\
\text { dont l'ambition commençait à troubler la } \\
\text { Grèce, et alarmait les Athéniens. Parti pour } \\
\text { la Macédoine comme député de sa patrie, } \\
\text { il en revint pensionnaire du prince, fut son } \\
\text { agent secret, et le principal auteur de cette } \\
\text { ruine de la Phocide qui mettait à découvert } \\
\text { la Grèce centrale. Aristocrate par bon ton, } \\
\text { et philippiste par vénalité, Eschine, durant } \\
\text { quatorze ans, s'opposa constamment aux } \\
\text { généreux efforts de Démosthène. }\end{array}$ & $\begin{array}{l}\text { En tanto, Esquines, hijo de padres humildes, } \\
\text { ejerce profesiones entonces tenidas por bajas, } \\
\text { la de atleta, la de cómico; Demóstenes goza } \\
\text { desde su juventud las ventajas del nacimiento } \\
\text { y de la fortuna. Más tarde Esquines, en vez } \\
\text { de rehabilitar su pasado con acciones y pen- } \\
\text { samientos nobles, á los cuarenta años llega a } \\
\text { la vida política y la comienza por donde otros } \\
\text { la terminan: por servir á los enemigos de su } \\
\text { patria y de la democracia ateniense. Represen- } \\
\text { tante de Atenas en la corte de Filipo, véndese } \\
\text { al oro macedonio, conviértese en agente se- } \\
\text { creto de las ambiciones del rey y contribuye } \\
\text { á la ruina de la Fócida, primer paso para la } \\
\text { conquista de Grecia. En tanto Demóstenes lu- } \\
\text { cha por la democracia, Esquines, aristócrata y } \\
\text { partidario del rey extranjero, opónese á todos } \\
\text { los proyectos patrióticos de aquel gran orador. }\end{array}$ \\
\hline
\end{tabular}

9 En la portada no se menciona a Ginard, quien firma la introducción. Como anónima hace constar esta versión Hernández (2008, p.285).

10 Por otro lado, tradujo también poemas de Byron (vol. 63, 1880) y el Ruy Blas de Víctor Hugo (vols. 42 y 44 , 1878). Además, en la $B U$ editó las obras de V. Balaguer (vols. 57, 1880). Como crítico destaca su Hombres y obras (Madrid, 1895) que incluye textos ya publicados sobre Calderón, Bossuet, Mirabeau, Byron, Víctor Balaguer y otros. 
Veamos el comienzo del discurso de Esquines, en el que sigue la citada traducción francesa de Stiévenart:

\begin{tabular}{|c|c|}
\hline STIÉVENART $1843 \mathrm{p}$ & BIBLIOTECA UNIVERSAL p. 19 \\
\hline $\begin{array}{l}\text { Vous voyez, ô Athéniens ! quel appareil on } \\
\text { déploie, quelle armée se range en bataille; } \\
\text { vous voyez certains hommes solliciter sur la } \\
\text { place publique l'abolition des règles et des } \\
\text { usages d'Athènes. Pour moi, je me présente } \\
\text { plein de confiance dans les dieux, puis dans } \\
\text { les lois et en vous, persuadé qu'auprès de } \\
\text { Vous l'intrigue ne prévaut jamais sur les lois } \\
\text { ni sur la justice. }\end{array}$ & $\begin{array}{l}\text { «Ya veis ¡oh atenienses! qué aparato se des- } \\
\text { plega, [sic] qué ejército se forma en batalla; } \\
\text { ya veis a determinados hombres solicitar en } \\
\text { la plaza pública la abolición de las leyes y de } \\
\text { las costumbres de Atenas. En cuanto a mí, } \\
\text { me presento lleno de confianza en los Dio- } \\
\text { ses, en las leyes y en vosotros; porque ante } \\
\text { vosotros la intriga no prevalecerá sobre las } \\
\text { leyes ni sobre la justicia. }\end{array}$ \\
\hline
\end{tabular}

La versión de Demóstenes sigue otra traducción, la de Jager-Chappuyzi, como muestra la comparación de las primeras líneas:

\begin{tabular}{|c|c|}
\hline JAGER-CHAPPUYZI, $1836^{2}$, p. 5 & BIBLIOTECA UNIVERSAL pp. 104-105 \\
\hline $\begin{array}{l}\text { Je commence, Athéniens, par demander aux } \\
\text { dieux immortels que, dans cette cause, ils } \\
\text { vous inspirent en ma faveur les sentimens de } \\
\text { bienveillance que j'ai toujours eus pour vous } \\
\text { et pour la république; [...] }\end{array}$ & $\begin{array}{l}\text { Comienzo rogando a los Dioses inmortales } \\
\text { que os inspiren hacia mí, atenienses, las mis- } \\
\text { mas disposiciones que siempre he sentido } \\
\text { por vosotros y por la República, }[\ldots]\end{array}$ \\
\hline
\end{tabular}

Encontramos citas de esta traducción en el manual de literatura de R. Blanco y Sánchez $(1925,71)$ y de la de ambos autores en el Manual de literatura nacional y extranjera de H. Giner de los Ríos (1889, II 115-116). El gran científico uruguayo Clemente Estable, al tratar de Demóstenes y Esquines en su obra El reino de las vocaciones, obra publicada en Montevideo en 1921, hace referencia en p. 38 a este volumen, del que toma información. Además de publicarse en España hubo una reimpresión en México (Veracruz-Puebla, La Ilustración, 1883) en una "Biblioteca Popular Económica" ${ }^{11}$.

\subsection{Antonio González Garbín}

\subsubsection{Introducción}

Antonio González Garbín (1836-1912), abogado de ideas republicanas, fue amigo de Nicolás Salmerón y gobernador civil de Almería. Enseñó literaturas clásicas en la Universidad de Granada y griego en la Central. Además de traducir a Plauto y a Jenofonte, es autor de un interesante manual de Literatura Latina, que supuso un hito en la enseñanza de esta materia en España (García Jurado 2013).

11 http://cdigital.dgb.uanl.mx/la/1080013710/1080013710.PDF. 


\subsubsection{Plauto y su teatro (vol. 116) ${ }^{12}$}

El volumen 116 incluye una traducción de La Aulularia y de Los $_{\text {cautivos }}{ }^{13}$. Se trata de una reimpresión de dos traducciones plautinas ya publicadas por González Garbín. Cada una tiene una historia editorial parcialmente diferente. La Aulularia apareció en 1877 por entregas en una publicación periódica, La revista de Andalucía, con notas, pero sin introducción ni texto latino ${ }^{14}$. A continuación fue editada por González Garbín en Granada en 1878 con introducción, texto latino y notas (Plauto 1878). En 1880 publicó González Garbín Los cautivos, también en Granada y asimismo con introducción, texto latino y notas (Plauto 1880). Encontramos ediciones que combinan las dos obras aparecidas de forma independiente, las cuales conservan sus fechas de publicación ${ }^{15}$.

En la Biblioteca Universal encontramos únicamente las traducciones y unas pocas notas en pp. 217-218. Esta es, pues, una versión simplificada de los textos de González Garbín, que originalmente o en un momento de su evolución constituyeron un «trabajo erudito»y un «instrumento de estudio» (Blanco 2015, 291). La nueva presentación resulta muy adecuada al contexto en que aparece y al objetivo puramente divulgativo de la colección. González Garbín era un filólogo decidido a la difusión de la obra plautina. Pero ello no le impide diferenciar entre las traducciones que «satisfacen las exigencias que la crítica y el buen gusto reclaman», como señala en el prólogo a su traducción de la Aulularia publicada en Granada en 1878 (Plauto 1878, 5-7, cf. Blanco 2015, 288) y las que no lo hacen. En definitiva, para González Garbín no todas las formas de divulgación de los textos clásicos valen ${ }^{16}$ y los encargados de realizar esta tarea son «los profesores que se consagran a la difícil enseñanza de las lenguas y literaturas clásicas y orientales» (p. 5). Es todo un manifiesto contra el amateurismo endémico y a favor de la profesionalización de la divulgación de los clásicos.

La versión de la $B U$ está precedida por una concisa, pero informativa, introducción titulada «Plauto y su teatro» por Juan Quirós de los Ríos ${ }^{17}$, publicada también en Revista de España $(115,1887,563-571)$. En ella, además de presentar la información más importante sobre el autor, subraya las útiles virtudes de su obra (pp. 13-14) y disculpa la «licencia de sus diálogos» (p. 12). Insiste en que sus obras son morales y ejemplo de buenas costumbres. Incluye juicios de autores antiguos favorables y desfavorables y da noticias sobre su pervivencia insistiendo en su influencia en el

12 Plauto, La aulularia y Los cautivos, comedias; versión castellana A. González Garbín, Madrid, Dirección y Administración, 1887. Reimpresiones: Madrid, Librería y Casa Editorial Hernando, 1928.

13 Esta traducción ha sido estudiada por Salomé Blanco (2015, 285-298), quien destaca la importancia singular de las versiones plautinas de Garbín y las considera un hito «en la consideración y recepción del comediógrafo latino en nuestro país» (p. 285).

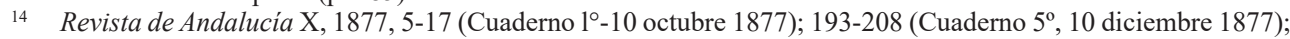
242-256 (Cuaderno 6º, 25 diciembre 1877).

15 Así el ejemplar Tus-8-9534 de la Biblioteca de Cataluña. Blanco $(2015,78)$ da noticia de otra publicación en Málaga, imprenta de Las Noticias y La Revista de Andalucía, 1880.

16 La reseña de la traducción de la Aulularia publicada en Revista contemporánea n. $.^{\circ} 26,3 / 1880,478-481$ insiste en esta idea: «Recomendamos este precioso trabajo a todos cuantos tengan aficiones al estudio de las antiguas literaturas, que es justo y meritorio popularizar cuando para ello se cuenta con personas tan autorizadas como el señor González Garbín, a quien no hemos de escatimar nuestro aplauso en la ocasión presente» (el subrayado es nuestro).

17 Quirós (¿-1894) fue Catedrático de latín en los institutos de Málaga y Granada. También ejerció la docencia en la Institución Libre de Enseñanza de Madrid y en la Universidad Literaria de Valencia. 
arte dramático, influencia que continúa en la actualidad (p. 16) ${ }^{18}$. En su opinión las representaciones en latín de Plauto deberían hacerse más frecuentes.

Comparemos la traducción de Garbín del comienzo del prólogo de Los cautivos con otra, publicada poco después, y realizada por Menéndez Pelayo (Plauto 1879).

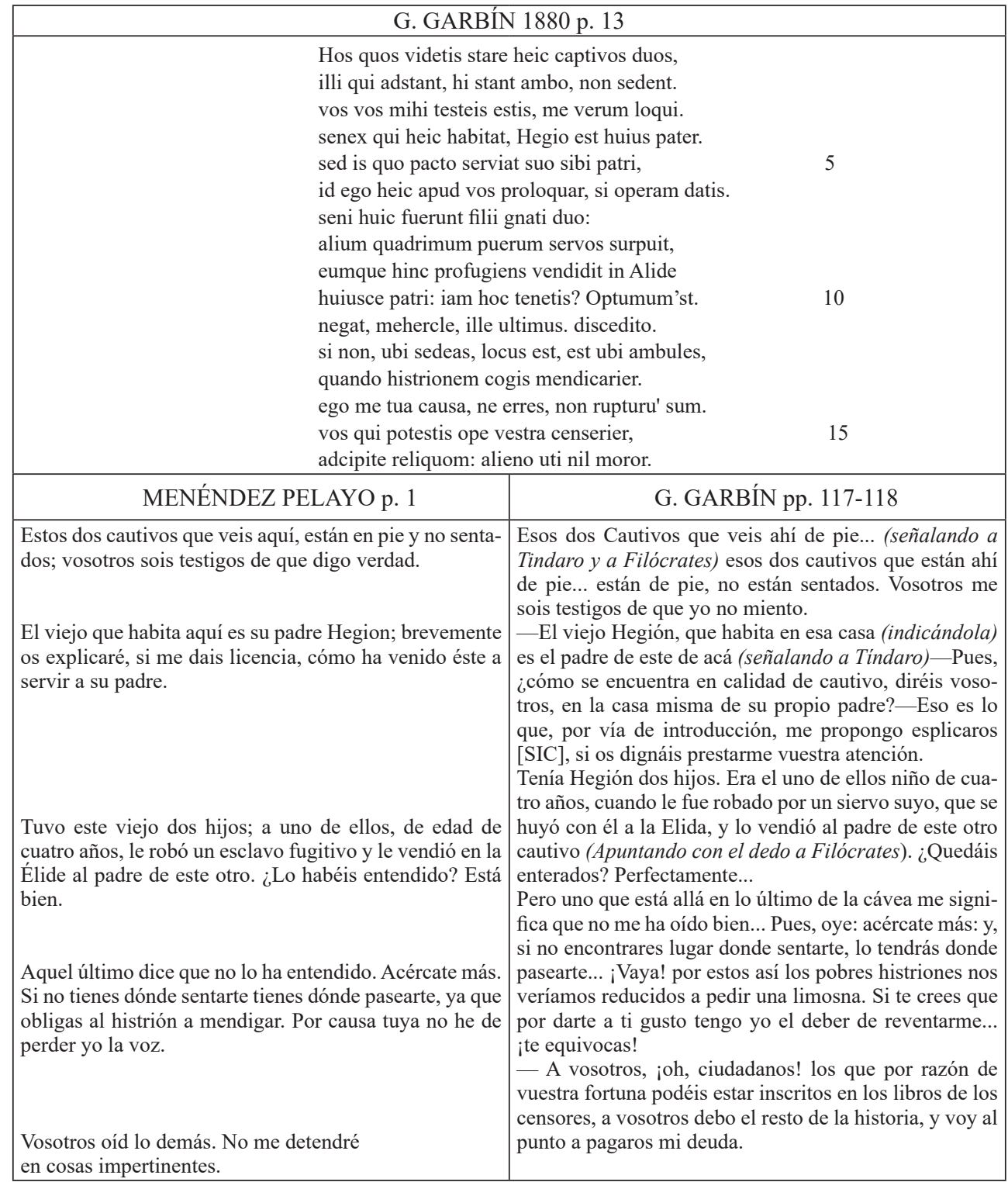

18 «el que supo ganar laureles inmarcesibles en la antigua escena romana, halos conquistado también en nuestros días, al ser representadas sus comedias, en su mismo original latino, en las márgenes del Spree, del Sena y del Manzanares, ni más ni menos que como lo fueran dos mil años ha bajo los muros del Capitolio». (pp.16-17) y «Entre los diferentes espectáculos realizados en Madrid, en socorro de los inundados de Murcia, fue uno de los más notables la representación, por los estudiantes de la Universidad, de la misma comedia latina Cautivos, puesta en escena bajo la sabia dirección de nuestro respetable y querido maestro el Doctor D. Alfredo Adolfo Camús.» (p.17). 
La traducción de Garbín es, a nuestro juicio, bastante 'mejor' que la de Menéndez Pelayo, por varias razones. 1) Incluye acotaciones que mejoran la reconstrucción de la representación. 2) Está atenta a los gags: en los versos iniciales hay una insistencia en el estar de pie que indica que los actores que hacían de hermanos probablemente se sentaban o movían en algún momento. Menéndez Pelayo resume los dos primeros versos, con lo que el efecto de la insistencia se pierde. 3) Muestra una mayor atención a detalles del texto: el mihi del verso 3 es vertido por Garbín y no por D. Marcelino. No obstante ninguno de los dos traductores refleja la diferencia hos ...illi...hi que apunta a que algunos de los actores estaban en movimiento. Por otro lado, en el verso 4 Garbín podría haber traducido heic por «en esta» para mantener el posible juego con huius. 4) Hace el texto más coloquial sin perder la elevación propia de la lengua literaria, con algún exceso («y si no encontrares lugar donde sentarte...»). 5) Explicita dobles sentidos e incluye información de realia, como en la versión de los versos 15-16. La traducción de Menéndez Pelayo busca resolver brevemente el problema y renuncia totalmente a la ambigüedad. La de Garbín busca una expresión que combine los dos sentidos, lo que resuelve de manera brillante. La traducción de Menéndez Pelayo parece casi un resumen de lo que dice Plauto. ¡Y lo es! Se trata en realidad, aunque en la publicación no se avise ${ }^{19}$, de un material redactado por el erudito santanderino para auxiliar al público en la comprensión de la ya citada representación en latín realizada en el Teatro Español en diciembre de 1879.

Respecto a la acogida de las traducciones plautinas de Garbín, sueltos en la prensa las recibieron con elogios (por ejemplo en El Demócrata 18/11/1880, 3 y El Liberal 12/12/1880, 3). En la reseña publicada en Revista contemporánea se considera que la obra plautina es muy desconocida en España y que ha sido «traducida a nuestra lengua en castiza y elegante prosa» (p. 478) por Garbín. Se insiste en que el traductor «hace también un verdadero trabajo crítico que viene á facilitar el conocimiento de la época de Plauto y de su importancia y significación en la literatura latina» (p. 479). Y en que, a juicio de una revista alemana, «se imita muy hábilmente el estilo de Plauto, sin hacer violencia á la lengua española» (p. 479). La obra es considerada un hito en el desarrollo de los estudios clásicos y Garbín un importante representante del grupo de quienes los impulsan: «El marqués de Morante, que en colaboración con D. Raimundo Miguel publicó el más notable diccionario latino-español, el ex-ministro Burgos y el afamado publicista Ochoa, traductores de Horacio y de Virgilio; Bendicho y algunos otros más, fueron los iniciadores de este movimiento restaurador, al cual puede contribuir muy eficazmente, por sus especiales dotes, el Sr. González Garbín, ilustradísimo catedrático en la Facultad de Filosofía y Letras de Granada» (p. 478) ${ }^{20}$. La crítica

19 M. Acci Plauti, Captivi, Matriti, Typis Fortanet, MDCCCLXXIX. (Portada interior) Los Cautivos, comedia de Marco Accio Plauto, traducida al castellano por M. M. P. Representada en el TEATRO ESPAÑOL en Diciembre De 1879 por alumnos de la Facultad de Filosofía y Letras, Madrid, Imprenta de Fortanet, Calle de la Libertad, núm. 29, 1879 (el subrayado es nuestro). Pero un artículo de La Ilustración Española y Americana (15/12/1879, 2) aclara: «El ilustre humanista Sr. Camús dirigió la parte literaria, y el erudito señor Menéndez Pelayo dio al público una castiza y fácil versión de la comedia, sin la cual el buen éxito de la obra hubiera sido imposible, pues el latín de Plauto no está al alcance de todos en el libro, y lo está al de muy pocos en la rapidez de la representación escénica». Sobre esta representación, S. Blanco (2015, 301-307); respecto a la reseña de La Ilustración, (2015, 303).

20 También en la introducción de nuestro volumen ofrece Juan Quirós una lista de críticos españoles estudiosos de Plauto y admiradores de su obra: «el sabio y eruditísimo Camús, el diligentísimo Costanzo, el diserto Canalejas y el laborioso y ameno González Garbín, honra este último de la Universidad granadina; todos afamadísimos 
del momento es consciente, pues, del proceso de profesionalización de la labor de divulgar a los clásicos, en la que las versiones plautinas de Garbín ocupan un puesto destacado. Por otro lado, una cita de cada obra traducida en este volumen aparece en el Manual de literatura nacional y extranjera de Hermenegildo Giner de los Ríos (1889, II 147-149).

\subsection{Fray Luis}

Como es sabido, aparte de su producción original, fray Luis desarrolló una labor traductora relativamente amplia, tanto de textos grecolatinos, como religiosos. Buena parte de los primeros son presentados en dos volúmenes de la $B U$ (uno dedicado íntegramente a estas traducciones, el otro sólo de forma parcial).

\subsubsection{Horacio por fray Luis (vol. 183) $)^{21}$}

Este volumen, que incluye, además de algunas poesías de fray Luis inspiradas en Horacio, traducciones atribuidas al agustino de odas del Venusino, va encabezado por una Advertencia inicial del escritor José Rogerio Sánchez (1876-1949), Catedrático de Instituto de Literatura (entre otros sitios, en el Instituto San Isidro y en la Escuela Superior de Magisterio) e importante divulgador. Dirigió la Revista de Segunda Enseñanza y publicó varios libros de texto. De orientación conservadora y de derechas ${ }^{22}$ desempeñó varios cargos políticos en el ámbito educativo.

Rogerio, tras subrayar la calidad de la versión de Fray Luis ${ }^{23}$, insiste en que el volumen pretende una «modesta popularización, cual corresponde al final de esta Biblioteca $\rangle^{24}$ (p. 6). Informa de que se ofrecen a veces dos versiones, una de Fray Luis y otra de otro autor. También de que se aportan composiciones de Fray Luis inspiradas en Horacio. Los textos están correctamente presentados e incorporan algunas pequeñas notas. Siendo una edición modesta y divulgativa ofrece un texto muy digno. Las odas de Horacio que aparecen traducidas son ${ }^{25}: 1,1$ (dos traducciones); 1,4 (dudosa); 1,$5 ; 1,13 ; 1,14 ; 1,19 ; 1,22 ; 1,23 ; 1,30 ; 1,33 ; 2,8 ; 2,10 ; 2,14 ; 2,18 ; 3,4$; 3,$7 ; 3,9 ; 3,10 ; 3,16 ; 3,27 ; 4,1 ; 4,13 ; 5,2$ [sic para el segundo epodo]. El número de versiones se acrecienta en un Apéndice: 1,5 (del Brocense); 1,19 (dudosa autoría); 1,24 (¿?); 1,33 (fray Luis); 2,8 (Lupercio Leonardo de Argensola); 2,8 (autoría desconocida); 2,9 (autoría dudosa); 2,16 (autoría dudosa); 3,9 (quizá de fray Luis). También se presentan en un segundo Apéndice odas de fray Luis inspiradas en Horacio: A D. Pedro Portocarrero (No siempre descendiendo); A Juan de Grial (Al canto

críticos y preclarísimos ingenios, quo han tejido con inmarcesibles laureles la eterna corona que ciñe las sienes de Plauto.» (p. 20).

21 Odas de Horacio traducidas por el maestro Fr. Luis de León, Madrid, Librería y Casa Editorial Hernando, [s. a.].

22 Lo que prueba que la colección, al menos en este momento, no tenía un sesgo político claro.

23 Se sigue la edición del P. Merino (1816), para el prologuista la mejor hasta el momento. También se consultan las notas de Menéndez Pelayo en la edición de la Academia y la edición de Mayans.

24 Insiste Rogerio en que «es conveniente que estas versiones se divulguen y que su lectura se haga fácil y cosa general» (p. 8), pues a las traducciones no se les ha dado la difusión que han alcanzado las poesías originales. Son pues necesarias estas «ediciones populares» (p. 9). La BU «dentro de sus fines modestos, viene contribuyendo a esa labor vulgarizadora» (p. 9).

25 La selección coincide con la que encontramos en la edición de las Poesías completas de fray Luis de C. Cuevas (Fray Luis 2001, 269-347), aunque allí encontramos además un fragmento de 4,7 (p. 340). 
y lira mía); Vida retirada; A Felipe Ruiz; Al licenciado Juan de Grijal (Recoge ya en el seno); Profecía del Tajo; De la Magdalena.

Es conocida la pasión que Menéndez Pelayo sentía por estos trabajos horacianos de Fray Luis. Además de la atención que les dedica en su Horacio en España, publicado en 1885, y las favorables opiniones que allí expresa (Menéndez Pelayo 1951b, 44), ya en 1882 había incluido buen número de las versiones de fray Luis en sus Odas de Q. Horacio Flaco traducidas e imitadas por ingenios españoles y coleccionadas por M. Menéndez Pelayo ${ }^{26}$. Son varias, pues, además de las ediciones del agustino que van apareciendo durante los siglos XIX y XX, las vías de popularización de estas traducciones horacianas de fray Luis. La $B U$ realiza con este volumen su aportación a esta tarea, típica de una corriente, que se remonta al siglo XVIII, en la que la divulgación de los clásicos se combina con la recuperación de los monumentos de la literatura española.

\subsubsection{Virgilio por fray Luis (vol. 5) $)^{27}$}

El volumen 5 de la colección está dividido en dos partes. En la primera se ofrecen una selección de obras en verso de fray Luis divididas en dos bloques: poesías originales (pp. 5-75) y traducciones e imitaciones de poetas profanos (pp. 76-124). Estas se limitan a las de Virgilio y, en concreto, a las diez Bucólicas y al libro primero de las Geórgicas. El resto del volumen (pp. 151-186) lo ocupan las poesías de san Juan de la Cruz. La edición carece de prólogo y cualquier tipo de anotación.

\section{Conclusiones}

1) La $B U$, fundada en 1872 por J. Pi y Margall como correlato económico de la $B A E$, ofrece hasta 1935 un crecido número de títulos (192), esencialmente obras de la Literatura Universal. Predominan las pertenecientes a la literatura española. De las demás literaturas destacan la francesa, la inglesa y la grecolatina. También se publican obras de divulgación del conocimiento en general.

2) Las características principales de los volúmenes son: precio extraordinariamente bajo, ediciones poco cuidadas con introducciones concisas y sin notas, intención eminentemente divulgativa y notable difusión.

3) La $B U$ se crea con el fin de ofrecer un instrumento de instrucción para obreros, estudiantes y, en general, personas de bajos recursos. Este es el público original de la colección. Los lectores acceden a los volúmenes comprándolos en las librerías o tomándolos en préstamo en bibliotecas ligadas a instituciones dirigidas a aumentar la instrucción de las clases humildes, como la biblioteca de la Casa del Pueblo de Madrid. No obstante, la presencia de volúmenes de la colección en bibliotecas de intelectuales de prestigio y el testimonio de algunos de ellos muestran que las clases cultas y acomodadas también los adquirieron y leyeron.

26 Una reedición de estas traducciones puede verse en Menéndez Pelayo (1951a) y otra en Cascón (1992).

27 Fray Luis de León y San Juan de la Cruz, Poesías, Madrid, Dirección y Administración, 1873. Reimpresiones: 1878, 1882, 1899, 1907, 1914 y 1918, cf. R. Lazcano González (1994, 152-153). 
4) A pesar de no ser el ámbito para el que están pensados, los volúmenes muestran también huellas de vinculación al contexto educativo.

5) Las traducciones de autores clásicos son a veces originales y otras han sido ya publicadas con anterioridad.

6) Los traductores pueden dividirse en: clásicos de la literatura española (fray Luis); publicistas y literatos (Á. Lasso de la Vega, Eduardo de Mier, el autor o autores de las versiones de Esquines y Demóstenes); filólogos: González Garbín. Aunque la mayoría de las traducciones continúa siendo obra de aficionados, se aprecia ya en la colección el lento proceso de profesionalización de la traducción de las obras clásicas que se va desarrollando en España precisamente en este periodo.

7) Las traducciones de Á. Lasso de la Vega utilizan el verso, están realizadas haciendo uso de versiones francesa y españolas anteriores y en ellas menudean despistes y errores. Sin embargo, se leen bastante bien, por lo que pudieron cumplir de forma razonable su labor de difusión de los autores.

8) De entre las otras traducciones destaca la de González Garbín, que, como hemos indicado, ofrece un ejemplo de versión científica y cuidada, aunque se ha reducido el aparato erudito respecto a publicaciones anteriores.

9) La difusión de las versiones de Horacio y Virgilio de fray Luis puede en parte vincularse a la corriente de recuperación del patrimonio literario y filológico hispano, especialmente de las obras de los Siglos de Oro, mediante la republicación de traducciones destacadas de autores clásicos realizadas en siglos pasados.

10) La $B U$ difundió con éxito las obras grecolatinas en ellas publicadas entre públicos muy diversos y se percibe un impacto particularmente importante en Hispanoamérica.

\section{Referencias bibliográficas}

Blanco López, S. (2015), Plauto durante la "Edad de Plata" de la Cultura Española (18681936), TD, UCM.

Blanco y Sánchez, R. $\left(1925^{3}\right)$, Elementos de literatura española e hispanoamericana, Madrid, Tipografía de la Revista de Archivos.

Carmona Vázquez, A. (2003), Coincidencias de lo trágico entre Eurípides y Federico García Lorca, Alcañiz-Madrid, C.S.I.C.

Cascón Dorado, A. (1992), Horacio, Odas y epodos. Traducción de los más grandes ingenios españoles, según la selección de Marcelino Menéndez Pelayo (incluye un apéndice con las mejores imitaciones, seleccionadas por el mismo autor). Introducción y notas de A. Cascón Dorado, Madrid, Lípari ediciones.

Cuevas, C. (2001), Fray Luis de León, Poesías completas. Propias, Imitaciones y Traducciones, Madrid, Castalia.

García Jurado, F. (2013), «De la Historia Latinae linguae a la "Historia de la lengua latina": literatura frente a lingüística. De Walchius a Stolz», Ágora. Estudos Clássicos em Debate $15,171-194$.

Giner de los Rios, H. (1889), Manual de literatura nacional y extranjera, antigua y moderna, 2 vols., Madrid, Victoriano Suárez. 
González Delgado, R. - González González, M. (2010), «La tragedia griega: Esquilo, Sófocles y Eurípides», en García Jurado, F. et al. (eds.), La Historia de la Literatura Grecolatina durante la Edad de Plata de la Cultura Española (1868-1936), Málaga, A. Malacitana, 177-195.

González Garbín, A (1878), T. Maccii Plauti Aulularia = la Marmita o el avaro, comedia latina de T. Maccio Plauto; versión... acompañada del texto original, con introducción y comentarios por A. González Garbín, Granada, Imprenta de Ventura Sabatel (primera portada: Teatro de Plauto. Traducción y comentario de las principales comedias de este poeta latino. I Aulularia, Granada, 1879; portada interior: 1878).

González Garbín, A. (1880), T. Maccii Plauti Captivi = Los cautivos, comedia del poeta latino T. Maccio Plauto; traducción [...] por A. González Garbín, Granada, Imprenta de Ventura Sabatel.

González González, M. - González Delgado, R. (2007), «Primeras traducciones de los trágicos griegos en lengua castellana», FlorIlib 18, 69-112.

Gountiñas Tunón, O. (1977), «Notas al Alceste», Actas del primer congreso internacional de estudios Galdosianos, Las Palmas de Gran Canaria, Cabildo Insular de Gran Canaria, 470-478.

Hernández Muñoz, F. (2008), Demóstenes, Discursos ante la asamblea, Tres Cantos, Akal.

Jager, J. N. (1834-1840), Chefs-d'oeuvre de Démosthène et d'Eschine: nouvelle traduction française, précédée d'un discours préliminaire et accompagnée de notes et d'analyses par M. l'abbé Jager, tomo II, París, A. Poilleux.

Jager, J. N.- Chappuyzi, V.-H. (1836), Discours sur la couronne: traduction française revue et corrigée avec soin [...] par M. Jager, deuxième edition, augmentée du texte pur en regard revue et corrigé par V.-H. Chappuyzi, Paris, Librairie classique de A. Poilleux.

Lazcano González, R. (1994), Fray Luis de León: Bibliografía, Revista agustiniana Vol. 31, $n^{\circ} 94,5-373$.

Martínez López, R. (2009), El legado bibliográfico de D. Miguel Mancheño y Olivares (18431922), Biblioteca de la Real Academia Hispano-Americana de Ciencias y Artes de Cádiz.

$<$ http://www.raha.es/gestorraha/images/catalogo/COLECCIoN_MANCHEnO.pdf $>$ [Consulta: 05/05/2016].

Menéndez Pelayo, M. (1879), Los cautivos, comedia de Marco Accio Plauto, traducida al castellano por M. M. P., Madrid, Imprenta de Fortanet.

Menéndez Pelayo, M. (1882), Odas de Q. Horacio Flaco traducidas e imitadas por ingenios españoles y coleccionadas por M. Menéndez Pelayo, Barcelona, E Doménech y Cía.

Menéndez Pelayo, M. (1951a), Bibliografía Hispano-latina Clásica. V. Horacio. Edición preparada por E. Sánchez Reyes, Santander, Aldus.

Menéndez Pelayo, M. (1951b), Bibliografía Hispano-latina Clásica. VI. Horacio. Edición preparada por E. Sánchez Reyes, Santander, Aldus.

Pérez Roldán, C. (1999), «La prensa republicana madrileña durante el siglo XIX. La Igualdad y El Combate como ejemplos de periódicos republicanos», Historia y comunicación Social 4, 317-339.

Stiévenart, J.F. (1843), Chefs-d'œuvre de Démosthène et d'Eschine, traduits sur le texte des meilleures éditions critiques par J.F. Stievenart, A Paris, chez Lefèvre Libraire-chez Carpentier Libraire-Éditeur. 